\title{
DIFICULDADES E DESCOBERTAS ENCONTRADAS NA INSERÇÃO DOCENTE DA EDUCAÇÃO INFANTIL: UM OLHAR SOBRE O INÍCIO DA CARREIRA DOCENTE E A SUA CONSTRUÇÃO
}

\section{ARTIGO ORIGINAL}

BARBOSA, Monalisa Raymundo ${ }^{1}$

BARBOSA, Monalisa Raymundo. Dificuldades e descobertas encontradas na inserção docente da educação infantil: um olhar sobre o início da carreira docente e a sua construção. Revista Científica Multidisciplinar Núcleo do Conhecimento. Ano. 06, Ed. 12, Vol. 01, pp. 33-49. Dezembro de 2021. ISSN: 24480959, Link de acesso:

https://www.nucleodoconhecimento.com.br/educacao/insercao-docente,

DOI: 10.32749/nucleodoconhecimento.com.br/educacao/insercao-docente

\section{RESUMO}

O início da carreira docente é marcado pela passagem da condição de aluno para professor, de estudante para profissional, representando, assim, a primeira etapa desenvolvimento profissional docente. Considerando esse cenário, este artigo tem como problema de pesquisa: discutir como ocorrem os momentos de dificuldades e descobertas do professor iniciante de Educação Infantil. O objetivo foi identificar e analisar as situações geradoras das dificuldades e reconhecer os momentos de descobertas encontradas por docentes durante sua inserção na Educação Infantil. Utilizamos a abordagem qualitativa e, como metodologia, foram utilizados questionários e grupos focais. A revisão de literatura apontou o panorama recente das pesquisas desenvolvidas na área e a evolução conceitual dos temas abordados. Esse estudo revelou as dificuldades das graduações, principalmente no que se refere à falta da prática em sala, não atendendo à complexidade docente, ao contexto escolar e à falta de formações específicas aos iniciantes. Com os dados

\footnotetext{
${ }^{1}$ Mestra em formação de professores, pedagogia, letras e magistério. ORCID: 0000-0002-5905-4762.

RC: 102529

Link de acesso: https://www.nucleodoconhecimento.com.br/educacao/insercaodocente
} 
obtidos na pesquisa, verificamos as seguintes necessidades: acompanhamento e apoio institucional às professoras principiantes; iniciativas em busca de processos formativos e as possibilidades de parcerias com os docentes mais experientes. $O$ ponto alto nessa pesquisa foi o apontamento feito pelos professores com relação às ações possíveis de serem implementadas para sanar esses momentos de dificuldades.

Palavras-Chave: Professores Iniciantes, Inserção Profissional, Descobertas, Desafios.

\section{INTRODUÇÃO}

O presente estudo observou que o início da carreira é uma fase que carece ser examinada, para assim apontar caminhos para uma reestruturação nos programas de formação inicial e continuada de professores. Evidenciou, dentre tantos aspectos, a necessidade da inserção docente em seus inúmeros contextos, revelada principalmente em função das dificuldades do professor iniciante em desempenhar sua tarefa de ensino.

De acordo com os estudos de Tardif, Raymond (2000, p. 217):

Os alunos passam através da formação inicial para o magistério sem modificar substancialmente suas crenças anteriores sobre o ensino. $E$, tão logo começam a trabalhar como professores, sobretudo, no contexto de urgência e de adaptação intensa que vivem quando começam a ensinar, são essas mesmas crenças e maneiras de fazer que reativam para solucionar seus problemas profissionais. Em segundo lugar, a trajetória profissional. Os saberes dos professores são temporais, pois são utilizados e se desenvolvem no âmbito de uma carreira, isto é, ao longo de um processo temporal de vida profissional de longa duração no qual intervêm dimensões de socialização profissional e também fases e mudanças.

Atualmente, quando a formação docente já está em nível superior, o cenário não é tão distinto do que outrora se tinha com a formação em nível médio, no chamado curso de Magistério. Ainda é comum observar a falta de preparo do professor iniciante no exercício de sua função, tendo em vista a dificuldade que possui em relacionar a teoria que aprende em sua formação acadêmica com a prática. Nota-se

RC: 102529

Link de acesso: https://www.nucleodoconhecimento.com.br/educacao/insercaodocente 
que há idealização da carreira com o término do curso, mas, ao defrontar-se com a realidade, muitos desses iniciantes acabam frustrados e desmotivados. Entretanto, quando há acolhida da equipe e da unidade, com um acompanhamento eficaz da prática desses iniciantes, eles acabam permanecendo na função docente e conseguem enxergar novas descobertas.

É preciso salientar que essa inserção docente pode ser marcada de momentos positivos e negativos, mas não significa que todos os iniciantes iniciam da mesma forma. Considerando esse cenário, este artigo tem como problema de pesquisa: discutir como ocorrem os momentos de dificuldades e descobertas do professor iniciante de Educação Infantil. $O$ objetivo foi identificar e analisar as situações geradoras das dificuldades e reconhecer os momentos de descobertas encontradas por docentes durante sua inserção na Educação Infantil.

\section{METODOLOGIA}

Refletindo sobre a adversidade do professor iniciante, na sua inserção na carreira, suas descobertas e dificuldades, esse artigo é um recorte da dissertação de Mestrado "Professores iniciantes na Educação Infantil: acolhida e acompanhamento", tendo como questão norteadora: analisar sobre como tem acontecido o ingresso profissional e como os professores iniciantes da Educação Infantil em uma rede municipal do interior paulista têm percebido seus primeiros anos de docência, cujos objetivos foram: conhecer como seu deu a inserção dos professores na carreira docente; reconhecer o que contribuiu para o seu desenvolvimento profissional; identificar as situações geradoras de apoio e acompanhamento e analisar como aconteceu sua experiência docente, nosso recorte será identificar e analisar a inserção docente, suas dificuldades, descobertas e sugestões apresentadas pelos pesquisados.

Os professores que participaram da pesquisa foram os iniciantes que ingressaram de 2014 a 2018. Para coleta de dados com esses docentes, utilizamos questionários e grupos focais. 
Para identificação dos participantes e preservação de sua identidade na pesquisa, no texto, eles são referidos pelas letras GF (Grupo Focal), seguidas de um número cardinal, que indica o número do participante. Ex.: GF32 = grupo focal participante 32. Já a letra $Q$ significa a resposta obtida por meio do questionário, seguida também de um número cardinal. Ex.: Q16 = questionário do participante 16.

\section{PERFIL DOS PROFESSORES INICIANTES}

Como instrumento de pesquisa, utilizamos questionários e 4 grupos focais, com o questionário em mãos, iniciou-se a verificação dos que estavam respondidos e os que estavam em branco. As questões quantitativas, apresentadas nesse instrumento, foram tabuladas pelo programa Sphinx e apresentadas em tabelas analisadas pela pesquisadora. Em seguida, com a leitura das respostas das perguntas abertas - a pré análise, listamos as respostas dessas perguntas e criamos indicadores de análise. Segundo Bardin (2011, p. 125), essa "é a fase da organização propriamente dita", de acordo com os objetivos da pesquisa, a fim de viabilizar a operacionalização.

Conforme já descrevemos, o questionário foi enviado para 52 (cinquenta e dois) professores iniciantes, apenas 03 (três) não foram devolvidos. Além disso, dos 52 questionários enviados, 12 não estavam dentro da proposta da pesquisa. Assim, restaram 37 (trinta e sete) professores iniciantes, que ingressaram na rede municipal e na Educação Infantil, entre os anos de 2014 a 2018, os quais se enquadraram aos objetivos do nosso estudo.

De acordo com as respostas nos questionários, a faixa etária dos professores era 24 a 42 anos. Com relação ao sexo, 36 eram mulheres e apenas 1 homem, verificando a evidência da feminização da docência.

De acordo com os estudos de Tardif (2013), as mulheres constituem grande parte da equipe de uma escola primária, o que revela a importância do trabalho feminino e que a presença maciça de mulheres na educação não é um fenômeno recente. 
No que se refere à formação dos participantes de nosso estudo, todos possuem graduação em Pedagogia, visto que, de acordo com a LDB 93/94/96, é obrigatória a formação em nível superior para o exercício da docência.

O tempo de docência dos professores pesquisados era, em média, de 1 a 3 anos, o que se alinha à pesquisa de Hurbeman (1995), segundo a qual denomina-se como iniciante o professor com até três anos de carreira.

\section{O INÍCIO DA CARREIRA}

O início de carreira é de suma importância na docência. Estudos de Marcelo Garcia (1999), Mizukami (2006), Nóvoa (2006), Huberman (1995), Imbernón (2001), Gatti (2005) entre outros, demonstraram os impasses que os professores iniciantes vivenciam na carreira docente, colocando em pauta diversas dificuldades que surgem desde a formação inicial.

No Brasil, a temática início da docência ainda é pouco explorada no campo acadêmico, porém, gradativamente, vem ganhando espaço com alguns pesquisadores interessados sobre como ocorre esse início da carreira docente.

Para Tardif (2002, p. 51), o início da carreira ocorre entre 1 e 5 anos, período em que:

Os professores acumulam, ao que parece, sua experiência fundamental. A aprendizagem rápida tem valor de confirmação: mergulhados na prática tendo que aprender fazendo, os professores devem provar a si próprios e aos outros que são capazes de ensinar.

O autor assegura que o professor iniciante tem 5 anos para aprender a prática, atuando muitas vezes na casualidade, na necessidade, na busca de acertar, para que, aos poucos, aproprie-se da prática, transformando-a em experiência e constituindo sua identidade profissional.

Para Marcelo Garcia (1999), não há exatidão na quantidade de anos para categorizar o professor como iniciante. $\mathrm{O}$ autor acredita que esse período abarca os

RC: 102529

Link de acesso: https://www.nucleodoconhecimento.com.br/educacao/insercaodocente 
primeiros anos, momento esse em que o professor faz a transição entre aluno para professor.

Em contrapartida, Huberman (1995) acredita que a fase de iniciação do professor compreende os três primeiros anos da carreira, caracterizada como "sobrevivência" e "descoberta". A sobrevivência está relacionada com o choque da realidade, em que o professor vivencia as dificuldades e a casualidade, verificando a distância de seus ideais com a vida cotidiana escolar:

[...] O choque do real" a confrontação inicial com a complexidade da situação profissional: o tatear constante, a preocupação consigo próprio ("Estou a me aguentar?"), a distância entre os ideais e as realidades quotidianas da sala de aula, a fragmentação de trabalho, a dificuldade em fazer face, simultaneamente, à relação pedagógica e à transmissão de conhecimentos, a oscilação entre relações demasiado íntimas e demasiado distantes, dificuldades com alunos que criam problemas, com material didático inadequado, etc...(HUBERMAN, 1995, p. 39)

De acordo com essas considerações, vê-se que o professor, ao sair de sua formação inicial, com seus sonhos e ideais, depara-se com a verdadeira realidade de uma sala de aula frustrando- se, ao perceber o distanciamento entre seus estudos e o cotidiano escolar.

Percebe-se, pelo que até aqui expomos, que não há um acordo entre os pesquisadores sobre os aspectos que envolvem a categorização e vivência do professor iniciante. A esse respeito, Lima (2006, p. 140) afirma que:

Não há consenso na literatura acerca da duração dessa fase. Huberman (1995) considera inicial a fase que se estende até o terceiro na de profissão; para Cavaco (1995), vai até o quarto ano de exercício profissional; Veeman (1988) argumenta que tal fase se prolonga até o quinto ano; Tardif (2002) defende que esse momento inicial compreende os cincos primeiros anos de profissão.

O que podemos afirmar, diante de todas as discussões dos autores, é que o início da carreira é uns dos momentos de suma importância para o profissional docente. Tratando-se de um momento de transição de estudante para professor, é o processo de sua constituição da identidade, um momento singular.

RC: 102529

Link de acesso: https://www.nucleodoconhecimento.com.br/educacao/insercaodocente 
Partindo desse pressuposto, a pesquisa realizada alinha-se com os estudos dos autores, principalmente quando os participantes do estudo afirmaram que a graduação não tem eficiência na prática docente. Esses professores participantes da pesquisa relataram algumas dificuldades referente à formação inicial:

Seria muito bom uma matéria na faculdade, que focasse somente na prática. (GF32) Acho que a maioria dos docentes não estão preparados para enfrentar a diversidade e os problemas sociais que se refletem na sala de aula. A formação é muito teórica. (Q16).

É perceptível a insatisfação dos professores com sua formação inicial. Eles se referem ao trabalho das universidades como algo sem alinhamento entre a teoria $x$ prática, já que o contexto escolar não é abordado nas aulas. Abordam o descontentamento com a realidade e as adversidades encontradas na prática, as quais não condizem com sua formação.

Tardif (2002) ressalta que certas condições são necessárias para que "estreia" na profissão seja mais fácil. São elas: ter turmas com as quais seja mais fácil lidar e um volume de trabalho que não consuma todas as energias do professor.

Nono (2011) enfatiza que o professor iniciante, ao se deparar com situações como: currículo a cumprir, ajuste ao conhecimento pedagógico e teórico com a prática, burocracias, especificidades de cada criança, indisciplina e outras situações em que há situações de necessidade e de urgência - já que inúmeras são as intercorrências que interferem na prática - acaba entrando em desespero. Trata-se, portanto, de um momento decisivo na carreira profissional, no qual, ao se dar conta do distanciamento que existe entre seu ideal educacional e o que se the apresenta como realidade, muitos desistem, por conta do sentimento de angústia, solidão, isolamento, despreparo e desamparo.

Nota-se, com essas considerações, que o professor iniciante, ao se deparar com a realidade, encontra um cenário não tão confortável quanto o que imaginava. Quando inicia em uma escola, as cobranças são exigidas da mesma forma como são impostas para um professor experiente, de modo que o iniciante tem que atingir os 
mesmos objetivos, lidar com famílias, diversidades dos alunos, gerir os conteúdos, atender à necessidade de cada aluno, ter manejo em sala, dentre outras circunstâncias que revelam um universo complexo.

As vivências nessa fase de entrada na carreira variam de docente para docente, dependendo de seu percurso, sendo conflituosa ou não. Em nosso estudo, foi possível observar que o grupo de professores iniciantes apresenta diferenças em razão do contexto organizacional de trabalho onde estiveram inseridos. Constatamos algumas dificuldades e descobertas encontradas nesse período inicial, as quais se devem a situações que nem sempre são exclusivas aos professores iniciantes, por isso a necessidade da formação centrada na escola.

\section{CONSTITUIÇÃO DA IDENTIDADE DOCENTE}

A construção da identidade docente se inicia desde o momento em que o professor era estudante. Todavia, o início, de fato, estabiliza-se na formação inicial, dando continuidade por toda sua vida profissional.

Antes mesmo de ingressar na carreira, os futuros professores já possuem conhecimentos e habilidades, tendo saberes ou não referentes a: conteúdos, familiarização e desenvolvimento das crianças, gestão de sala de aula, entre outros. Muitos buscam conhecimento na literatura, porém não possuem a experiência para um ensino eficaz, faltando-lhes habilidades para alcançar a aprendizagem do aluno e suas peculiaridades. (CALIL, 2014, p. 61).

Marcelo Garcia (2009) afirma que a identidade docente não é automática e sim construída e modelada. $O$ autor enfatiza que é um processo individual e coletivo, configurado por representações subjetivas acerca da profissão docente. $O$ autor ainda ressalta que a constituição da identidade está associada à percepção do ofício por parte dos próprios docentes e pelo contexto em que está inserido.

A construção da identidade do professor é um processo flexível e dinâmico que leva em consideração todo seu contexto escolar, político e social. Nessa perspectiva,

RC: 102529

Link de acesso: https://www.nucleodoconhecimento.com.br/educacao/insercaodocente 
Marcelo Garcia (2010) ressalta que a constituição da identidade docente é individual, variando de acordo com a história do docente e com suas características sociais, podendo ser também uma construção coletiva de acordo com seu contexto atual.

Pelo exposto, vemos que o aparato teórico visitado em nosso estudo, entende que o início da docência é de fundamental importância no processo formativo do professor. Trata-se de um momento com inúmeras dificuldades, desafios e tensões, os quais, ao mesmo tempo que representam obstáculos também contribuem para novas aprendizagens e para a construção da identidade profissional, delineando o seu modo de ser professor. (MARCELO GARCIA, 1999; NONO; MIZUKAMI, 2006).

De acordo com Nóvoa (1995), ao construir a identidade profissional, o professor sente a necessidade de explorar os saberes advindos de sua trajetória. Segundo o autor, esse caminhar formativo é muito importante para a formação profissional, pois os conhecimentos obtidos constroem seu arcabouço teórico, transformando-se em um processo contínuo para construção da sua identidade docente.

Uma questão, aplicada no questionário e no grupo focal de nosso estudo, referia-se à formação continuada para o auxílio do cotidiano em sala de aula. Acerca disso, os docentes iniciantes relataram que:

Precisamos de formações continuadas de acordo com as nossas dificuldades (GF33) Oferecer uma formação específica, além de propiciar uma convivência vigorosa com outros professores com trocas coletivas de experiência. (Q14).

Os professores evidenciaram a necessidade e o interesse pelas formações, as quais contribuam para o contexto escolar, o que se torna imprescindível para preencher as lacunas deixadas na graduação. Freire, (1996, p. 43) relata que "na formação permanente dos professores, o momento fundamental é a reflexão crítica sobre a prática". Há que se pensar, portanto, em maneiras para auxiliar estes docentes iniciantes em seu dia a dia, com formações específicas e continuadas.

Tendo visto essas constatações, salienta-se a necessidade da formação continuada para os professores iniciantes, que contribua para o processo inicial de 
aprendizagem e que leve em consideração as diferentes fases da carreira docente. Essa formação deve considerar necessidades docentes e as especificidades dos diversos contextos.

\section{NECESSIDADES FORMATIVAS E COMUNIDADE DE APRENDIZAGEM}

Para iniciarmos esta seção, referente às necessidades formativas dos professores iniciantes e às comunidades de aprendizagens, é de extrema importância mencionar os estudos de André (2015), intitulada Políticas de formação continuada e de inserção à docência no Brasil, que trata das políticas de formação continuada, principalmente as formações voltadas à inserção docente. Essa autora coletou dados em 15 Secretarias de Educação de estados e municípios brasileiros, visando identificar: os processos de formação continuada adotados pelas Secretarias visitadas, os responsáveis das formações, os conteúdos e metodologias das formações as demandas e as avaliações.

A autora afirma que identificou ações sendo realizadas em algumas Secretarias, porém de forma isolada. Na Secretaria de Educação do Espírito Santo, os professores, após ingressar através de concurso público, participam de uma seleção com duas etapas: processo de formação de 60 horas, com temas atuais da educação, oficinas e estudos pedagógicos; após essa fase, fazem uma prova eliminatória. Ao final, a partir dos dados retirados do último concurso (2010), constatou-se que, dos 704 professores, apenas 2 desistiram e 2 foram reprovados, o que representa número menor de professores enfrentando dificuldades no período de inserção profissional. (ANDRÉ, 2015)

$\mathrm{Na}$ Secretaria Municipal de Jundiaí, ao ingressar, os professores têm 30 dias de capacitação, antes de adentrar na sala de aula, já recebendo os seus salários. Já a Secretaria de Educação de Sobral oferece um programa específico para os professores iniciantes, que consiste em uma experiência de formação e 
aprimoramento da prática pedagógica, suprindo as lacunas na formação dos docentes. (ANDRÉ, 2015)

Diante dos estudos da autora, notam-se as poucas iniciativas dos municípios e estados para a inserção docente e a formação continuada. (ANDRÉ, 2015)

Neste estudo, os professores iniciantes tiveram a oportunidade de mencionar como deveria ser realizada a inserção docente, por parte do diretor, professor coordenador e a equipe docente:

\section{Diretor:}

Uma gestão que norteie o professor iniciante (GF32). Orientações sobre o cotidiano (GF21).

Uma reunião inicial com a gestão com explicações e esclarecimentos sobre o planejamento e rotina com projetos (Q35).

Professor Coordenador:

A rotina da escola foi passada, na questão de atividades, conteúdo, currículo faltou um pouco, há falta de comunicação, de uma forma geral, não ficamos sabendo de nada, fico sabendo só quando alguém comenta (GF23).

Curso preparatório ou formação em horários distintos de HTPC, que ajude a compreender a realidade da sala de aula (Q16).

Maior tempo para troca de experiências e conhecimento com os professores mais experientes (Q28).

Equipe docente:

Apoio dos profissionais escolares, compartilhar informações, ideias e experiências (Q33).

Buscar apoio dos demais docentes da equipe, pedindo ajuda e sugestões quando necessário, ver a equipe como um suporte (Q32).

Nos relatos acima, os professores iniciantes evidenciaram ações que não envolvem nenhuma questão financeira, por isso, podem ser facilmente utilizadas nas unidades escolares. Solicitaram para os diretores orientações básicas referente ao dia a dia; já aos professores coordenadores, os docentes, em sua maioria, pediram formações e

RC: 102529

Link de acesso: https://www.nucleodoconhecimento.com.br/educacao/insercaodocente 
momentos de trocas com os professores mais experientes; já para a equipe docente requereram apoio no contexto. Esses dados podem servir de suporte para rede pesquisada, sendo útil na elaboração de formações para equipe gestora apresentar aos professores iniciantes.

Verificamos, à luz desses dados, o quão a formação de professores é totalmente importante e fundamental para que o ensino-aprendizagem seja eficaz. Essa formação deve ser contínua, baseada no redimensionamento do desenvolvimento profissional.

Para o autor Libâneo (2011), a formação de professores visa à reflexão da prática educativa, com mudanças qualitativas no desenvolvimento e na aprendizagem de sujeitos que desejam se preparar profissionalmente para ensinar.

Imbernón (2001) acredita que, na formação permanente, há cinco linhas ou eixos de atuação:

1. A reflexão prático-teórica sobre a própria prática mediante a análise, a compreensão, a interpretação e a intervenção sobre a realidade. A capacidade do professor de gerar conhecimento pedagógico por meio da prática educativa.

2. A troca de experiência entre iguais para tornar possível a atualização em todos os campos de intervenção educativa e aumentar a comunicação entre os professores.

3. A união da formação a um projeto de trabalho.

4. A formação como estímulo crítico ante práticas profissionais como a hierarquia, o sexismo, a proletarização, o individualismo, o pouco prestígio etc., e práticas sociais como a exclusão, a intolerância etc.

5. O desenvolvimento profissional da instituição educativa mediante o trabalho conjunto para transformar essa prática. Possibilitar a passagem da experiência de inovação (isolada e individual) à inovação institucional.

Partindo dessas premissas apresentadas por Imbernón (2001), a formação profissional não se findará apenas na parte técnica, mas sim no terreno prático, com reflexões dos sujeitos sobre sua prática docente, realizando constantemente o 
processo de reflexão. $\mathrm{O}$ autor ainda ressalta que a formação deve ser um processo que dote o professor de conhecimentos, habilidades e atitudes, para nutrir profissionais reflexivos e investigadores. É preciso que essa formação leve o professor a desenvolver instrumentos intelectuais para facilitar as capacidades reflexivas sobre a própria prática docente.

Acerca desse papel edificador da formação profissional, Marcelo Garcia (1999) defende que a formação de professores é um espaço para adquirir conhecimento, investigar propostas teóricas e práticas, com um único objetivo: melhorar a educação dos alunos.

Os professores participantes de nossa pesquisa se mostraram interessados em formações continuadas, dirigidas ao seu contexto, voltadas para a prática escolar. De certa forma essas formações tendem a suprir lacunas deixadas pela formação universitária. Sobre isso, Freire (1996, p. 43) afirma que "na formação permanente dos professores, o momento fundamental é a reflexão crítica sobre a prática. É pensando criticamente a prática de hoje ou de ontem que se pode melhorar a próxima prática".

Considerando as afirmativas dos autores, Mizukami (2011), embora não se referindo unicamente ao professor iniciante, defende que todos os professores devem fazer parte de uma comunidade de aprendizagem, trabalhando com os pares. Para isso, é preciso que a equipe gestora identifique as necessidades e dificuldades individualmente e proporcione momentos de discussão, oferecendo a oportunidade de conhecer novas práticas com profissionais mais experientes, os quais podem dar sugestões e apoio aos novatos.

Sabemos que nas escolas temos profissionais em diversas etapas da carreira, o que torna o contexto privilegiado. São espaços coletivos propícios para discussões e para reflexões sobre a prática docente, com a utilização dos conhecimentos em momentos específicos. Essas situações de interação são fundamentais não apenas

RC: 102529

Link de acesso: https://www.nucleodoconhecimento.com.br/educacao/insercaodocente 
para o professor iniciante, já que a criação desses espaços seria útil para a inserção de todos os docentes.

\section{INSERÇÃO DOCENTE: DIFICULDADES E DESCOBERTAS}

Como temos mostrado ao longo dessa discussão, o início da carreira docente é repleto desafios, principalmente no que se refere à integração dos professores iniciantes no contexto escolar.

Esse processo de inserção docente é caracterizado por peculiaridades, conforme salienta Lima (2004), além de ser marcado por inúmeras dificuldades.

Para Marcelo Garcia (1999, p. 28) é conceituado como "período de confrontação inicial do professor com as complexidades da situação profissional"

Mariano (2006, p. 44) encontrou a definição para esse choque com a realidade:

a diferença entre o idealizado nos cursos de formação e o encontrado na realidade cotidiana das escolas. Esse choque é marcado pelo sentimento de sobrevivência, quando o iniciante se questiona: o que estou fazendo aqui? Em contrapartida, os professores podem experimentar o sentimento de descoberta, o sentir-se profissional, ter a sua sala de aula. É esta descoberta a mola propulsora para a permanência na profissão.

A partir dessas conceituações, reiteramos que é de extrema importância compreender o professor em seu início de carreira, pois é nesse momento que ocorrem os desânimos e as desistências. Considerando essas dificuldades encontradas na carreira do professor iniciante, os professores participantes dos Questionários e dos Grupos focais de nosso estudo apontaram vários momentos em que se mostraram inseguros.

Papi e Martins (2010) confirmam que o início da carreira é fundamental para que se construam saberes necessários ao longo da profissão. Torna-se um período decisivo para sua permanência, pois são, os primeiros anos, os mais difíceis ou fáceis, dependendo das condições encontradas pelo docente em seu exercício inicial, e das relações encontradas nas equipes e com outros colegas.

RC: 102529

Link de acesso: https://www.nucleodoconhecimento.com.br/educacao/insercaodocente 
Por meio dos dados coletados em nossa pesquisa, apresentamos a seguir a análise das dificuldades encontradas no início da carreira dos participantes do estudo. No que refere à adaptação com a realidade pelos professores de nossa pesquisa, obtivemos os seguintes apontamentos:

Agora eu me sinto confortável, no começo eu chorava, pensava que isso não era para mim, achava que tinha escolhido a profissão errada, mas tudo é uma questão de adaptação (GF23).

No começo foi bem conturbado, minha sala é bem agitada, eu não estava acostumada e nem eles, foi difícil, até eu pegar o ritmo deles demorou (GF21).

Às vezes, eu ficava olhando as outras professoras mais antigas e pensava, "Meu Deus" como ela consegue? Queria ser uma mosquinha para ficar lá na sala dela, para ver o que ela faz, as minhas crianças não me obedecem (GF13).

Observamos, com essas constatações, que o início da carreira implica diversos fatores que podem ser vivenciados ou não. Nas falas relatadas acima, os professores demonstraram insegurança em sua inserção, momento esse já superado conforme os relatos. Entendemos, portanto, que é um período de aprendizagens intensas, é o início da construção do desenvolvimento profissional, aprendizagem essa que, na rede municipal pesquisada, deverá acontecer dos dois lados, tanto do professor iniciante quanto à comunidade escolar.

A esse respeito, Tardif (2002), conforme já apresentamos, afirma que os saberes dos professores são temporais e se desenvolvem no contexto escolar, pois a carreira é também um processo de socialização. Trata-se de um processo de marcação e de incorporação dos indivíduos às práticas $e$ às rotinas institucionalizadas das equipes de trabalho, exigindo que os professores se adequem a essas práticas e rotinas e não o inverso. Para o autor, saber viver numa escola é tão importante quanto ensinar em uma sala de aula, assim a inserção do professor exige que ele assimile também saberes práticos específicos aos contextos de trabalho, como suas rotinas, valores e regras. 
Ao serem questionados sobre as dificuldades ao chegar à escola, os professores disseram que:

Minha maior dificuldade era implementar uma rotina em sala de aula, a minha sala tinha passado por muitas eventuais e eu também não sabia direito como era uma rotina, fui trocando experiências, para implementar e para eles entenderem (GF41). Nós iniciantes vamos fazendo e aprendendo, os alunos estão ali esperando uma posição de liderança, mas a gente não sabe direito o que está fazendo, a rotina é o primeiro grande desafio (GF42).

Tinha dificuldade com o controle da sala, a rotina, o dormitório, manter aquela serenidade, eu olho as mais antigas e penso: "Meus Deus como elas conseguem? (GF13).

Notamos a dificuldade dos professores em estabelecer a rotina dentro da sala de aula.

Como isso é de suma importância para a organização de seu trabalho, compreender a rotina da sala de aula e da escola como um todo deveria tornar-se um momento natural nesse processo de inserção docente. De suma importância também é o auxílio da equipe gestora, assessorando esses profissionais em suas dificuldades e no engajamento escolar.

Para Lobato (2013), a rotina, além de facilitar a sequência de atividades diárias, também é um elemento que possibilita a organização do ambiente e o uso do tempo, pois, quando a rotina é bem planejada e executada, torna-se extremamente positiva no processo de educação.

Conforme Tardif e Raymond (2000), a socialização se dá na carreira, passando por um processo de marcação e incorporação dos indivíduos às práticas e rotinas institucionalizadas das equipes de trabalho. Essa incorporação, conforme já dissemos aqui, exige que os iniciantes se adaptem a essas práticas e rotinas e não ao inverso, pois, do ponto de vista do profissional e da carreira, o saber "viver" na escola é tão importante quanto saber ensinar em sala de aula. Nesse sentido, os autores afirmam que a inserção numa carreira e o seu desenrolar exigem que os

RC: 102529

Link de acesso: https://www.nucleodoconhecimento.com.br/educacao/insercaodocente 
professores assimilem também saberes práticos específicos relacionados aos lugares de trabalho, suas rotinas, valores, regras etc.

Ficou evidente que os professores participantes do nosso estudo não tiveram tranquilidade ao ingressar na função docente, talvez por muitas cobranças, pressão, responsabilidade de ter sua própria sala, pelo medo, ansiedade e até a falta de orientação de que tratam os autores supracitados.

Uma grande referência até os dias atuais, no que tange à inserção docente é o postulado de Huberman (1995) acerca do ciclo vital dos professores. O autor revela, como primeira fase do ciclo, a entrada na carreira, correspondente aos dois ou três primeiros anos de ensino, os quais são marcados pela sobrevivência e descoberta, vividos em paralelo.

Em uma das questões da nossa pesquisa, foi perguntado aos professores se, nesse início da profissão docente, houve alguma descoberta. As respostas evidenciaram que, no contexto em que se encontravam no momento do estudo, alguns professores já tinham se apropriado do manejo escolar, realizando diversas descobertas e modos de trabalhar:

A minha descoberta foi conseguir fazer os semanários e planos de ensino, porque no início eu não tinha noção (GF12).

Para mim foi a questão de desenvolvimento, de você ver que a criança passou, se desenvolveu, de ver que ela entendeu (GF21).

A sensação mais gostosa é você ver que seu aluno evoluiu, você pega uma criança que não sabia escrever, aí ela vem e mostra "olha tia fiz isso", é a melhor sensação, a criança realizar uma atividade que você propôs (GF33).

É o aprendizado, você ver que eles já sabem escrever o nome, contar... (GF34).

Notamos, com esses apontamentos, que não só de momentos desagradáveis vivem os professores iniciantes. Eles nos relataram como foram as grandes descobertas que aconteceram durante esse processo de inserção e o quanto evoluíram no seu desenvolvimento profissional, construindo, assim, sua identidade docente. 
Mencionaram suas gratificações com 0 desenvolvimento dos alunos e o preenchimento de documentos, o que representa uma grande conquista para seu início de carreira, apesar de todas as adversidades do contexto escolar.

Nesse sentido, seguem as falas dos momentos de satisfação dos professores:

A prática, o dia a dia, muita paciência, e a confiança que tudo é um processo. (GF41). Eu acho que é a parte de desenvolvimento da criança, nós vemos a alegria deles em querer aprender, este ano estou com uma turma de jardim, nossa foi muito lindo ver eles se desenvolvendo, lendo, e também a parte afetiva, a gente cria um vínculo tão gostoso, o reconhecimento das mães, que vem agradecer, que fala que você fez a diferença na vida do filho, isso tem acontecido comigo esse ano, isso faz querer continuar (GF22).

Se você perceber no dia a dia não tem muito segredo, se conseguir manter um padrãozinho de atividades, você vai percebendo qual interessa as crianças, qual dá para repetir, minha descoberta é saber que consigo (GF13).

Um dia que você consegue fazer aquilo que parecia impossível, você sai feliz né. (GF13).

Fica evidente a satisfação dos participantes da pesquisa ao serem reconhecidos e se reconhecerem como professores, algo que se construiu a partir da junção dos conteúdos (específicos e didáticos) dos recursos e da prática, principal elemento nos relatos de satisfação dos docentes.

\section{CONCLUSÃO}

Partindo do pressuposto que a questão norteadora era identificar e analisar os momentos de dificuldades e descobertas do professor iniciante de Educação Infantil. O presente artigo, nos permite afirmar que o início da carreira é um período muito complexo, crucial para o desenvolvimento profissional e a constituição da identidade docente.

O processo formativo, longamente apontado aqui como decisivo para esse período de iniciação na docência, possibilita a constituição da identidade do professor. Ressaltamos, todavia, que esse processo nunca se esgota, ele se estende ao 
contexto em que o professor está inserido, em momentos de troca de experiências, cursos formativos, entre outros.

Os professores iniciantes, que participaram da pesquisa mencionada nesse artigo, mostraram que sabem o que faz falta nessa inserção docente, pois, no momento do estudo, eles estavam vivendo a etapa de descobertas e de dificuldades. Os relatos desses docentes permitiram constatar que há que se investir em formações docentes, principalmente com uma política pública específica ao professor iniciante.

Considerando os aspectos teóricos aqui mencionados, entendemos que existe a necessidade de um programa de inserção planejado para receber adequadamente os professores iniciantes. Esse programa precisa voltar-se para todas as suas dificuldades e descobertas, apontadas acimas nos dados obtidos em nossa pesquisa, e outras que emerjam da realidade de cada unidade escolar e de cada grupo de profissionais.

Ressaltamos a necessidade de um olhar apurado para o professor iniciante e para a formação de professores, para que, durante as propostas de formação inicial e continuada, possam refletir sobre sua prática, na busca de mudanças de visões, advindas do senso comum, acerca do aprendizado dos alunos e de suas práticas em sala de aula.

\section{REFERÊNCIAS}

ANDRÉ, M. Políticas de valorização do trabalho docente no Brasil: algumas questões. Ensaio: aval. Pol. Públ. Educ., Rio de Janeiro, v. 23, n. 86, p. 2013 230, 2015.

BRASIL. Ministério da Educação. LDB - Lei de Diretrizes e Bases da Educação Nacional. Lei n. 9.394/96, de 20 de dezembro de 1996. Disponível em http://portal.mec.gov.br/seesp/arquivos/pdf/lei9394_ldbn1.pdf . Acesso em: 23/07/2021?

RC: 102529

Link de acesso: https://www.nucleodoconhecimento.com.br/educacao/insercaodocente 
CALIL, A. M. G. C. A formação continuada no município de Sobral/CE. 2014. $202 f$ Tese (Doutorado em Educação) - Pontifica Universidade Católica de São Paulo - PUC, 2014.

CAVACO, M. H. Ofício do professor: o tempo e as mudanças. In: NÓVOA, A. (Org.). Profissão professor. Portugal: Porto Editora, 1995. p. 155-191.

FREIRE. P. A Pedagogia da autonomia: saberes necessários à prática educativa. São Paulo: Paz e Terra, 1996.

HUBERMAN, M. O ciclo de vida profissional dos professores. In: NÒVOA. A. (org.) Vidas de professores. Portugal. Porto Editora. 1995. p. 31-61

IMBERNÓN, F. Formação docente e profissional: formar-se para a mudança e a incerteza. 2. Ed. São Paulo: Cortez, 2001. 119 p. (Coleção Questões da Nossa Época, 77).

LIBÂNEO, José Carlos. Panorama do ensino da didática, das metodologias específica e das disciplinas conexas nos cursos de pedagogia: repercussão na qualidade da formação profissional. In: Longarezi. A. Puentes, R. V. (org). Panorama da didática - ensino e pesquisa. Campinas: Papirus. 2011

LIMA, E.F. (Org.) Sobrevivência no início da docência. Brasília: Liber Livros, 2006.

LOBATO, M. J. S. Aspectos Gerais da Rotina Escolar na Pré-escola. Saberes, Natal-RN, v. 1, n. 8, ago. 2013, 73-75.

MARCELO GARCIA, C. Formação de Professores: para uma mudança educativa. Porto: Porto, 1999.

MARCELO, GARCIA - A identidade docente: constantes costumes. Revista Brasileira de pesquisa sobre formação docente, v. 01, n. 01. p. 109-131, 2009 
MARIANO, A. L. S. O início da docência e o espetáculo da vida na escola: abrem-se as cortinas. In: LIMA, E. F. (Org.). Sobrevivências no início da docência. Brasília: Líber Livro Editora, 2006. p. 17-26.

MIZUKAMI, M. G. N. et al. Escola e aprendizagem da docência: processos de investigação e formação. São Carlos: EdUFSCar, 2006.

MIZUKAMI, A. N. Professores iniciantes, o papel da escola em sua formação. Porto Alegre: Ed. Mediação, 2011

NONO, M. A.; MIZUKAMI, M. da G. N. Processos de formação de professores iniciantes. Revista Brasileira de Estudos Pedagógicos, Brasília, v. 87, n. 217, p. 382-400, set/dez. 2006.

NÓVOA, A. (Coord.). Os professores e sua formação. Lisboa, Portugal: Dom Quixote, 1995.

NONO, M. A.; MIZUKAM, M. G. N. Professores iniciantes: o papel da escola em sua formação. Porto Alegre: Medição, 2011.

PAPI, S. e MARTINS, P. As pesquisas sobre professores iniciantes: algumas aproximações. Educação em Revista. Belo Horizonte, v. 26, n. 03, p. 39-56, dez/2010.

TARDIF, M. Saberes docentes e formação profissional. Petrópolis: Vozes, 2002.

TARDIF, M.; RAYMOND, D. Saberes, tempo e aprendizagem do trabalho no magistério. Educação e Sociedade: Revista quadrimestral de Ciência da Educação/ de Estudos Educação e Sociedade (CEDES), Campinas, n. 73, p. 209$244,2000$.

VAILLANT, D.; MARCELO GARCIA, C. Ensinando a ensinar: as quatro etapas de uma aprendizagem. Curitiba: UTFPR, 2012.

RC: 102529

Link de acesso: https://www.nucleodoconhecimento.com.br/educacao/insercaodocente 
Enviado: Outubro, 2021.

Aprovado: Dezembro, 2021.

RC: 102529

Link de acesso: https://www.nucleodoconhecimento.com.br/educacao/insercaodocente 